\title{
Ectopic Liver Tissue Mistakenly Diagnosed as a Right Atrial Myxoma
}

\author{
Mohanad Soliman ${ }^{1}$, Olalekan Akanbi ${ }^{1}$, Amr Salem ${ }^{2}$, Mahmoud Khreis ${ }^{1}$, Ahmed Abdel-Latif ${ }^{3}$ \\ 1. Internal Medicine, University of Kentucky School of Medicine, Lexington, USA 2. Internal Medicine, Baystate Medical \\ Center, Springfield, USA 3. Cardiology, University of Kentucky School of Medicine, Lexington, USA
}

Corresponding author: Mohanad Soliman,gmmohanad@gmail.com

\begin{abstract}
Myxomas, metastatic tumors, thrombi, and vegetations top the differential diagnosis list of cardiac masses. We present a case of ectopic liver tissue, a far less common etiology of a right atrial mass, discovered incidentally on transthoracic echocardiography (TTE) of a 37-year-old female with multiple comorbidities who was referred to our facility for further management of left popliteal artery occlusion and right lower extremity cellulitis. We discuss further the categories, proposed pathogenesis, diagnostic approach, and potential complications of ectopic liver tissue.
\end{abstract}

Categories: Cardiology, Internal Medicine, Gastroenterology

Keywords: atrial mass, abberant, malignant transformation, cardiac mri, spect, herniation

\section{Introduction}

Aberrant liver tissue is an exceedingly rare condition that may have clinical implications ranging from mechanical compression to malignant transformation [1]. Typically, the aberrant hepatic tissue is found in the abdominal organs; however, it has also been described in the thoracic cavity [2]. In extremely rare occasions, ectopic hepatic tissue can present as a right atrial mass. Fujimoto and colleagues [3] described the first case of intracardiac aberrant liver tissue mistakenly diagnosed as a right atrial tumor in 1998.

\section{Case Presentation}

A 37-year-old Caucasian female with a past medical history significant for spina bifida complicated by paraplegia and neurogenic bladder, kyphoscoliosis with multiple spine surgeries, hypertension, sinus tachycardia, depression, and multiple episodes of right lower leg cellulitis presented as a transfer to our tertiary medical center for further management of a left popliteal artery occlusion and right lower extremity cellulitis. Her daily medications were trazodone, Celexa, tolterodine, propranolol, Wellbutrin, and hydrochlorothiazide.

Received 12/20/2018 Review began 12/24/2018 Review ended 01/05/2019 Published 01/10/2019

\section{() Copyright 2019}

Soliman et al. This is an open access article distributed under the terms of the Creative Commons Attribution License CC-BY 3.0., which permits unrestricted use, distribution, and reproduction in any medium, provided the original author and source are credited.
On physical examination, she was calm, cooperative, and in no acute distress. She weighed $65 \mathrm{~kg}$ and was $134 \mathrm{~cm}$ tall. Her blood pressure was $119 / 85 \mathrm{~mm} \mathrm{Hg}$, heart rate 101 per minute, temperature $98.8^{\circ} \mathrm{F}$, respiratory rate 18 per minute, and arterial oxygen saturation of $96 \%$ on 2 liters nasal cannula. Head and neck examination was normal, and she had moist oral mucosa with no oral thrush or ulcers noted. There were no abnormal lung or heart sounds. The abdomen was soft, non-distended, non-tender with no rebound or guarding, and normal bowel sounds. Physical examination revealed kyphoscoliosis of the back, underdeveloped paraplegic lower extremities with bilateral sensory loss, and intact distal pulses in the left foot with warm pink toes. The right lower leg and foot were swollen, erythematous, and non-tender with bullae of serosanguinous fluid. Her laboratory tests were normal, except for hypokalemia, with a potassium level of $2.4 \mathrm{mmol} / \mathrm{L}$ and lactic acid of $1.6 \mathrm{mmol} / \mathrm{L}$.

The vascular surgery team was consulted. She was started on a heparin drip for left popliteal artery thromboembolism and the recommendation was made for transthoracic echocardiography (TTE) and antiphospholipid syndrome screening.

The TTE showed a cardiac mass in the right atrium extending into the inferior vena cava (IVC) (Figure 1). For further identification of the mass, cardiac magnetic resonance imaging (MRI) was done which showed a normal left ventricular ejection fraction of $57 \%$, right ventricular dilatation with moderately reduced systolic function of $36 \%$, and a mass-like structure projecting over the right atrium with the appearance most suspicious for a diaphragmatic caval foramen herniation of liver parenchyma encroaching on the right atrium (Figure 2). A sulfur colloid nuclear single-photon emission computed tomography (SPECT) study also confirmed this finding (Figure 3). She continued inpatient treatment with anticoagulation and antibiotics during which she was seen by cardiology who recommended outpatient follow-up with cardiothoracic surgery for evaluation for potential surgical excision of the right atrial mass that was found to be herniated liver tissue. 


\section{Cureus}

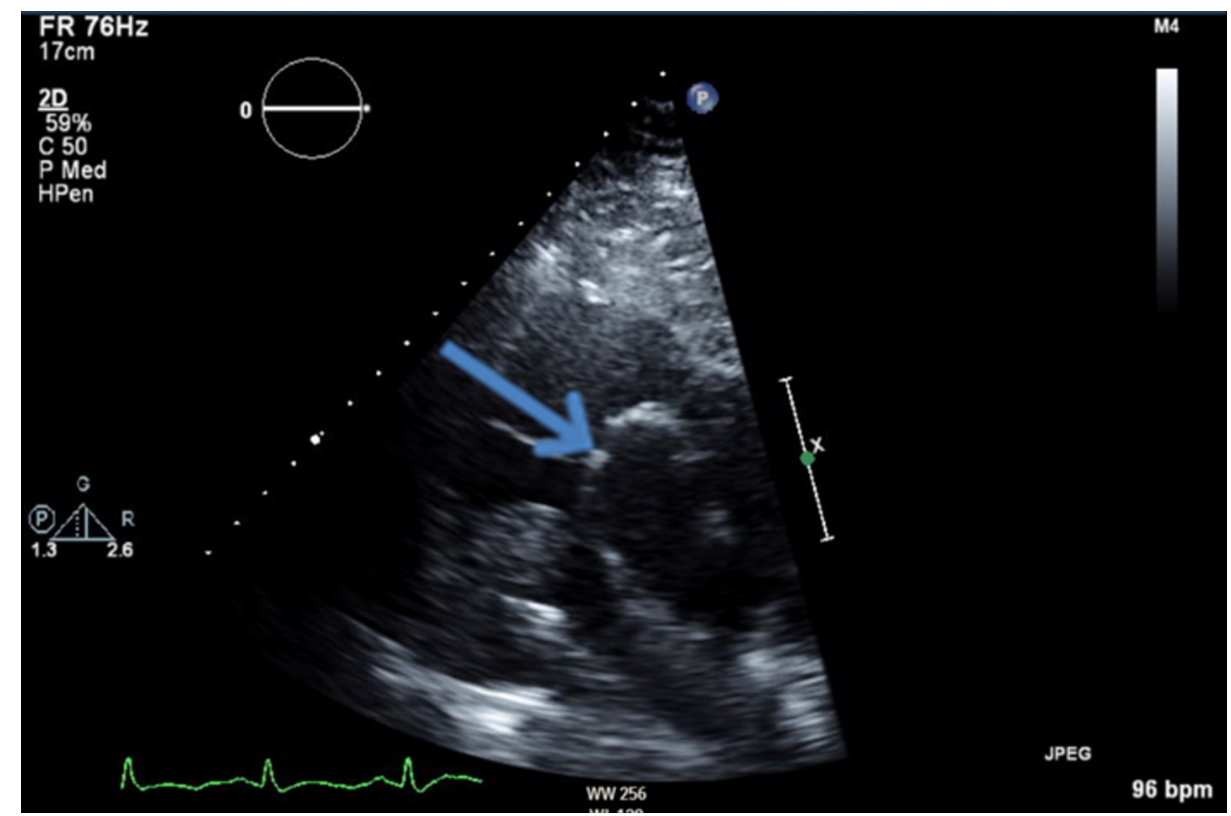

FIGURE 1: Echocardiography - short axis view at the aortic valve level showing the right atrial mass

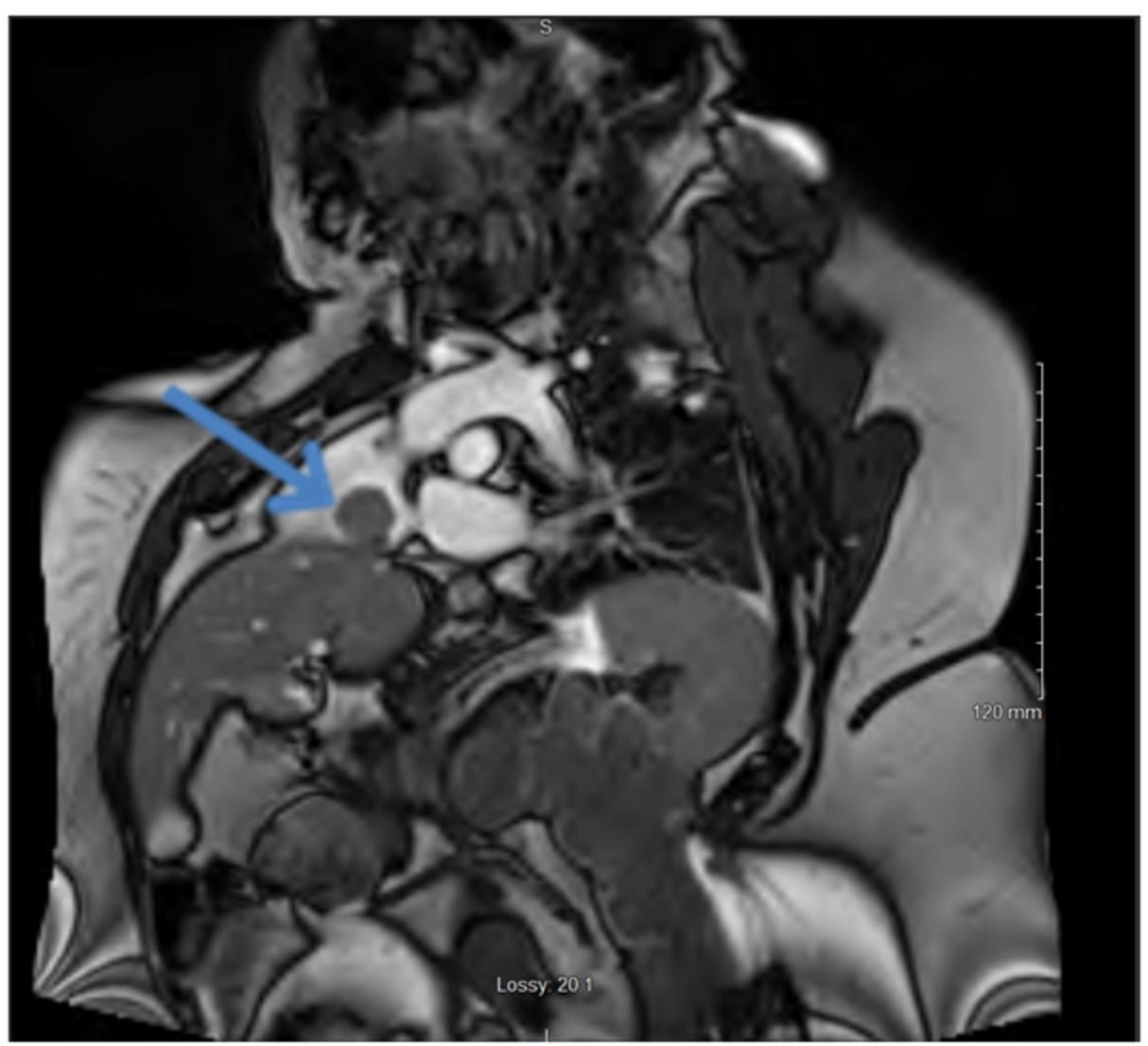

FIGURE 2: Cardiac magnetic resonance imaging (MRI)

MRI image of cine sequence cutting through a right atrial mass showing the origin of the mass from the liver 


\section{Cureus}

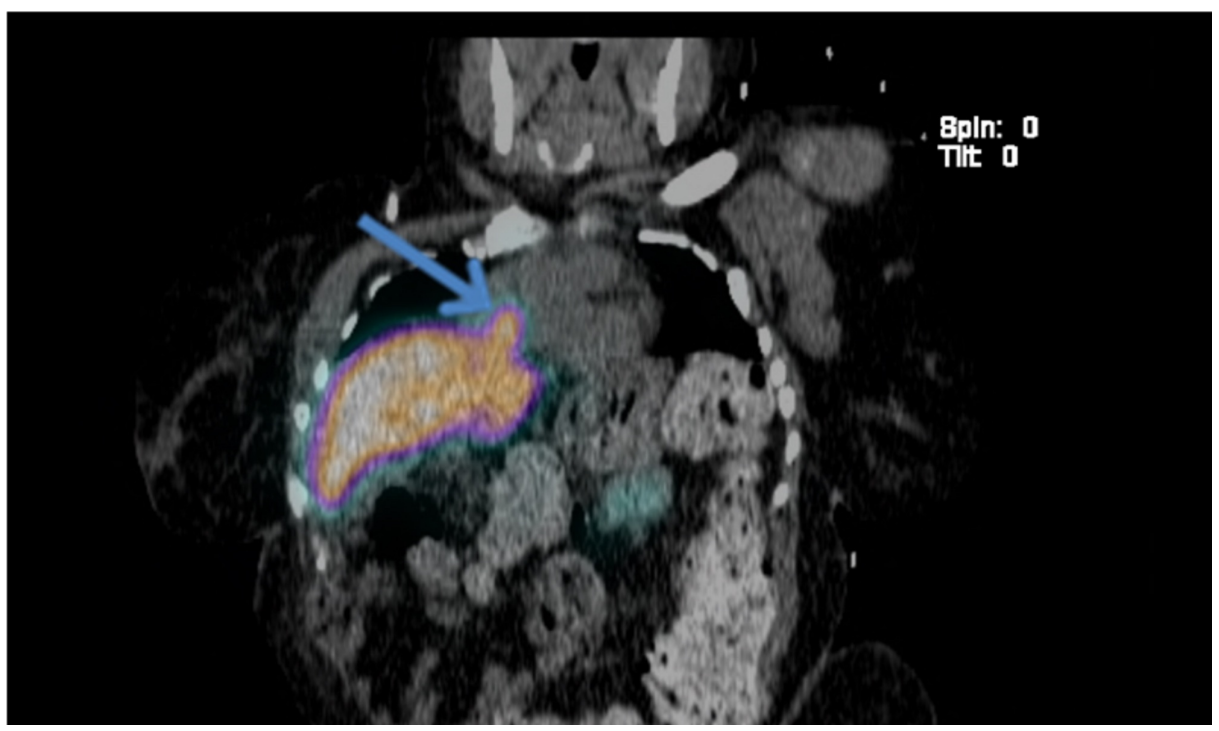

FIGURE 3: 99m Tc-sulfur colloid SPECT/CT showing the liver and liver hernia uptake

SPECT/CT: single photon emission computed tomography/computed tomography

\section{Discussion}

The vast majority of intracardiac tumors are secondary to metastatic disease. Primary cardiac tumors are extremely rare and $75 \%$ of the time are benign. Myxoma is the most common primary cardiac tumor [4].

Intracardiac mass differential diagnosis is broad. It includes tumor, thrombus, vegetation, or foreign body. It also can be an extremely rare presentation of a heterotopic liver that has herniated through the vena cava into the right atrium, which can be mistakenly diagnosed as a right atrial tumor [3].

Ectopic liver is a rare condition that can be classified into four categories: (i) an accessory liver lobe attached to the liver, (ii) a large accessory liver lobe with a connecting stalk to the liver, (iii) an ectopic liver without connection to the liver, and (iv) microscopic ectopic liver tissue [4]. The present case is consistent with the second type of ectopic liver tissue. Typically, the presentation of aberrant hepatic tissue is in the abdominal cavity; however, it has been reported in the thoracic cavity [5]. There have been a few cases in which ectopic liver parenchyma has been described as a right atrial mass [6-8].

In the absence of trauma, the pathogenesis of heterotopic liver tissue is still unclear. Controversial theories have been documented in an effort to explain this liver tissue aberrancy. One theory proposed that it is a congenital defect of the septum transversum, embryonic tissue that differentiates into both the diaphragm and ventral mesentery of the foregut [1]. However, authors of another case report hypothesized that there can be hematogenous migration of hepatic cells with regenerative capacity even after intrauterine development. They supported their hypothesis with the absence of a detectable right atrial mass on TTE performed 18 months prior to the patient's presentation [9].

Although this ectopic liver tissue was discovered as an incidental finding during TTE, it can have serious clinical implications. Chapman-Fredrick et al. described a case of inferior vena cava (IVC) obstruction by a hernia liver mass [10]. This can lead to downstream venous congestion and a higher risk of thromboembolic complications. Another clinical implication is the malignant transformation of aberrant liver tissue. Matsuyama et al. reviewed 100 cases of aberrant hepatic tissue and reported that 28 patients were found to have hepatocellular carcinoma on a pathologic review of the tissue [11]. This potential risk of carcinogenesis should increase the urgency for closer follow-up, surgical excision with negative margins, and a careful pathologic review of the ectopic tissue.

Most cardiac masses are found incidentally during routine cardiac imaging. TTE is most commonly used, due to its affordability, portability, widespread availability, lack of exposure to ionizing radiation, and ability to provide anatomical and functional information of the heart. However, there are pitfalls to TTE. It may not be able to differentiate herniated liver masses from an atrial myxoma, secondary malignant masses, and in some cases, thrombus or vegetations. These limitations are resulting from the poor acoustic window, being operator-dependent, and having a narrower field of view [12]. Cardiac magnetic resonance imaging (MRI) might be of more value as it offers several advantages over TTE, such as a larger unrestricted field of view, superior soft-tissue contrast, operator independence, and consistent reproducibility [13]. Thus, cardiac MRI 
is a very helpful diagnostic tool when an intracardiac mass cannot be characterized by TTE.

\section{Conclusions}

In exceedingly rare occasions, heterotopic hepatic tissue can present as a right atrial mass that can be mistakenly diagnosed as a right atrial myxoma or other more common etiologies of cardiac mass. Cardiac MRI should be the next step when the TTE study is not able to clearly characterize the right atrial mass. As this ectopic liver tissue carries a risk of malignant transformation, close monitoring and surgical excision with safety margins should be considered.

\section{Additional Information \\ Disclosures}

Human subjects: Consent was obtained by all participants in this study. Conflicts of interest: In compliance with the ICMJE uniform disclosure form, all authors declare the following: Payment/services info: All authors have declared that no financial support was received from any organization for the submitted work. Financial relationships: All authors have declared that they have no financial relationships at present or within the previous three years with any organizations that might have an interest in the submitted work. Other relationships: All authors have declared that there are no other relationships or activities that could appear to have influenced the submitted work.

\section{References}

1. Sarsam S, Arsene C, Abu-Rashed K, Liu Q, Rajagopal R: Heterotopic hepatic polyp identified in the right atrium. J Med Cases. 2012, 3:274-76. 10.4021/jmc652w

2. Caygill CP, Gatenby PA: Ectopic liver and hepatocarcinogenesis. Eur J Gastroenterol Hepatol. 2004, 16:72729. 10.1097/01.meg.0000131037.92864.df

3. Fujimoto S, Nakagawa Y, Mizuno R, Dohi K, Otsuji H, Nakano H: A case of hepatic hernia with echocardiographic findings simulating right atrial tumor. J Am Soc Echocardiogr. 1998, 11:680-82. 10.1016/S0894-7317(98)70047-1

4. Kamiya H, Yasuda T, Nagamine H, Sakakibara N, Nishida S, Kawasuji M, Watanabe G: Surgical treatment of primary cardiac tumors: 28 years’ experience in Kanazawa University Hospital. Jpn Circ J. 2001, 65:315-19. $10.1253 /$ jcj.65.315

5. Zonca P, Martinek L, Ihnat P, Fleege J: Ectopic liver: different manifestations, one solution. World J Gastroenterol. 2013, 19:6485-89. 10.3748/wjg.v19.i38.6485

6. Brustmann H: Heterotopic liver in the right cardiac auricle. Ann Diagn Pathol. 2002, 6:248-49. 10.1053/adpa.2002.34732

7. Moody WE, Hübscher SG, Rooney SJ, Doshi SN: Intracardiac ectopic liver mimicking atrial myxoma-an unusual cause for a right atrial mass. Int J Cardiol. 2016, 209:210-12. 10.1016/j.ijcard.2016.02.055

8. Trocciola SM, Balsam LB, Yee H, Gianos E, Srichai MB, DeAnda A Jr: Ectopic liver: an unexpected finding in a right atrial mass. Ann Thorac Surg. 2011, 92:715-18. 10.1016/j.athoracsur.2011.01.100

9. Izzo BA, Stoudenmire CJ, Byrd BF 3rd: Ectopic liver tissue presenting as a right atrial mass on echocardiography. CASE (Phila). 2012, 1:958-60. 10.1016/j.case.2017.05.007

10. Chapman-Fredricks J, Birusingh R, Ricci M, Rodriguez M: Intracaval liver with cardiac extension. A new development anomaly?. Fetal Pediatr Pathol. 2010, 29:401-406. 10.3109/15513815.2010.505622

11. Matsuyama M, Sugiura S, Kakita A, Sato Y, Kuroda M: Hepatocellular carcinoma arising from ectopic liver tissue in the spleen producing insulin-like growth factor II. Pathol Res Pract. 2011, 207:124-26. 10.1016/j.prp.2010.09.003

12. Mankad R, Herrmann J: Cardiac tumors: echo assessment. Echo Res Pract. 2016, 43:R65-R77. 10.1530/ERP16-0035

13. Attili AK, Gebker R, Cascade PN: Radiological reasoning: right atrial mass. AJR Am J Roentgenol. 2007, 188:26-30. 10.2214/AJR.06.0754 